\title{
Diagnóstico, plan de tratamiento y restauración de un diente con el síndrome del diente fisurado: reporte de caso y seguimiento de siete años
}

Diagnosis, planning, and restoring treatment of cracked syndrome tooth: case report - 7-year follow-up

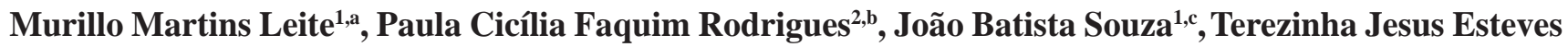
Barata $^{1, \mathrm{c}}$,Lawrence Gonzaga Lopes ${ }^{1, \mathrm{c}}$.

\section{RESUMEN}

Se describe y reporta el diagnóstico, tipo de tratamiento y seguimiento de un caso con el síndrome del diente fisurado. Una paciente de 26 años acusaba sensibilidad a los cambios térmicos y a la oclusión en el lado izquierdo de la mandíbula. Al examen clínico se observó dos grietas o fisuras pigmentadas en las superficies bucales y linguales de la pieza 36. La colocación de una restauración directa con resina compuesta resolvió los síntomas y alivió por completo el dolor. Dicha situación persistió incluso en el control realizado 7 años después. El diagnóstico y tratamiento para el caso descrito dio como resultado un completo alivio y mantenimiento de la situación alcanzada siete años después.

PALABRAS CLAVE: Síndrome de diente fissurado, fracturas de los dientes, materiales dentales.

\section{SUMMARY}

This case report describes a cracked tooth syndrome and reports on its diagnosis, type of treatment and monitoring. A 26-year-old female patient complained of thermal and chewing sensitivity in the left side of her mandible. Clinical examination revealed two pigmented cracks on the buccal and lingual surfaces of tooth 36 . The choice of a direct restorative treatment with composite resin led to the resolution of symptoms and complete relief of pain, which persisted in a 7-year monitoring period. The diagnosis and treatment of the case described here resulted in complete pain relief and maintenance of normal conditions seven years later.

KEY WORDS: Cracked tooth syndrome; tooth fractures; dental materials.

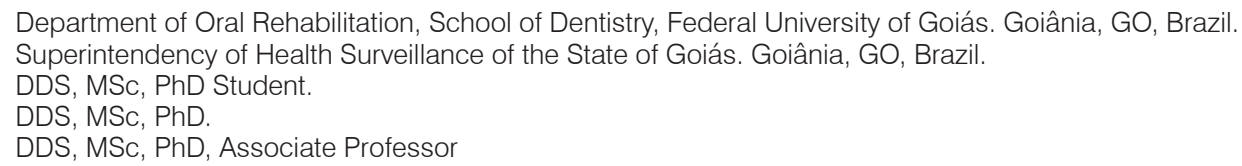




\section{INTRODUCTION}

Tooth fracture is one of the most important causes of tooth loss, second only to caries and periodontal disease, and one of the three major dental conditions that cause pain $(1,2)$. The cracked tooth syndrome is a cluster of signs and symptoms associated with the presence of a crack in enamel and dentin (3). The diagnosis of this syndrome requires knowledge of its etiology, signs and symptoms, depth and direction, tissues involved, prognosis and possible treatments $(1,3)$. The differential diagnosis, essential for the definition of treatment, includes cracks in enamel only [no symptoms], vertical cracks and incomplete fracture [cracked tooth] (4).

Patients usually report feeling discomfort and pain when chewing with the compromised tooth $(1,4)$. Restored teeth are the most commonly affected, but healthy teeth or teeth with conservative restorations may also have cracks (3-5). An excessive load resulting from the accidental bite on an object or a piece of hard food may cause a crack when applied to a small contact area of a restored tooth $(2,3)$. Parafunctional behaviors, such as bruxism, or emotional stress that may trigger dental clenching are also important factors in the etiology of the cracked tooth syndrome $(3,4)$. Furthermore, cusp inclinations are related with one of the etiologies from such syndrome, which has a relevant role in the cracking process (6).

Treatment should be defined according to crack location and depth $(3,4,7)$. In spite of many treatment alternatives be suggested, most of the clinical decisions taken for the treatment are not based on scientific evidences (8). When the cracked tooth syndrome diagnosis is confirmed, an initial occlusal adjustment should be made to remove occlusal interferences and relieve symptoms (7), and then a restoration should be made (9). On the other side, it has been advised that the restoring procedure take place after the endodontic treatment $(5,8,10)$, as well as the dental extraction $(8,11)$.

This report describes a case of cracked tooth syndrome treated with a posterior direct restoration with composite resin and followed up for seven years to control clinical signs and symptoms.

\section{Case report}

A 26-year-old woman sought dental care at the School of Dentistry of the Federal University of Goiás, Goiânia, Brazil, with a chief complaint of thermal and chewing sensitivity in the mandibular left side. According to the patient, the pain was intermittent, localized and rated as nine on a 0-10 visual analogue scale (VAS), in which 0 was no pain and 10 , the most intense pain.

Clinical examination revealed two Class I amalgam restorations in mandibular first molar, one in the central sulcus and the other in the buccal sulcus (Figures 1 and 2). They appeared to be secondary carious lesions and were classified as clinically unsatisfactory. According to the patient, sensitivity to hot and cold had started five months before and the restoration was made 18 years earlier. There were two pigmented cracks, one on the buccal (Figures 1 and 2) and the other on the lingual surface. Occlusal contacts were checked with articulating paper and revealed a larger contact area on the occlusal surface than in other areas. Periapical and interproximal radiographs did not suggest the presence of a crack (Figure 3). Was performed tooth percussion and pulp vitality test with cold air and the patient responded with sensitivity.

To confirm the diagnosis, the restorations were removed to examine the crack directly. Anesthesia with $2 \%$ mepivacaine hydrochloride $(20 \mathrm{mg} / \mathrm{mL})$ and 1:100,000 epinephrine $(0.01 \mathrm{mg} / \mathrm{mL})$ was applied, and the tooth was isolated with rubber dam. After the restorations were removed using a round carbide bur, caries lesion was confirmed, and was removed using a low-speed rotating instrument. The crack extended buccolingually. According to the restorative plan, first a bevel was placed on the buccal surface extending to the occlusal surface using a \#1012 diamond bur, and $37 \%$ phosphoric acid was applied to enamel (30 seconds) and dentin (15 seconds) on the buccal surface. A two-step adhesive (Adper Single Bond, 3M ESPE, St. Paul, MN, USA) was applied and light-cured for 20 seconds. Composite resin was placed incrementally, first using Filtek Supreme WD (dentin; 3M ESPE, St. Paul, MN, USA) and then Filtek Supreme A2E (enamel; 3M ESPE, St. Paul, MN, USA). Curing was gradual: 10 seconds for each layer and 40 seconds in the end. 


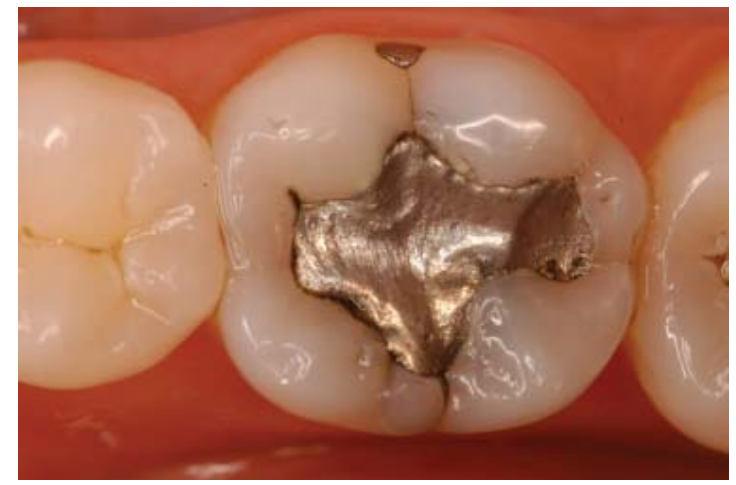

Figure 1. Initial occlusal view.

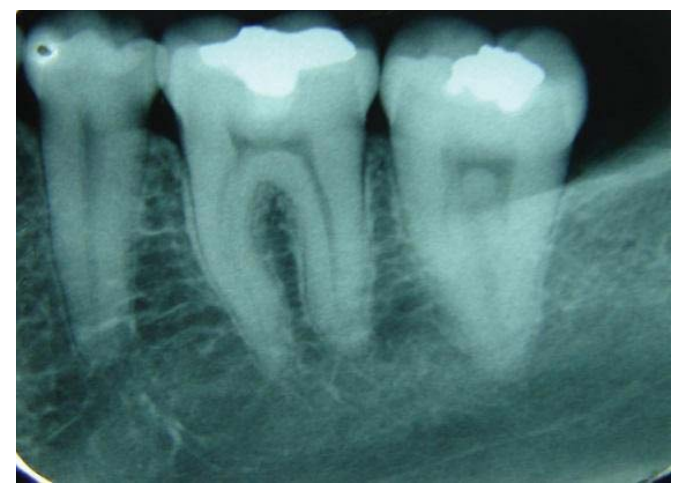

Figure 3. Baseline radiograph.

The occlusal restoration was initiated after the buccal restoration was ready. In the deepest region of the occlusal cavity, a glass-ionomer cement (Magic Glass F, Vigodent, Rio de Janeiro, Brazil) was used as a liner, and then covered with a small \#7 wax plate for seven minutes to avoid syneresis and ensure setting. After that, 37\% phosphoric acid was applied only to enamel, and the self-etching adhesive system (Adper Single Bond) was applied to both enamel and dentin and light-cured for 20 seconds. The following resins were used sequentially: Filtek Supreme A2D, Filtek Supreme A2E, Filtek Supreme WD, and Filtek Supreme CT (3M ESPE, St. Paul, MN, USA). The resin was placed into the cavity incrementally to reconstruct the tooth progressively and to ensure contraction stress relief and that its color matched the shade of the tooth closest to the restoration. Light-curing was gradually made being 10 seconds for each layer and 40 seconds in the end.

After checking occlusion with articulating paper and setting with a fine-grained diamond bur, the occlusal

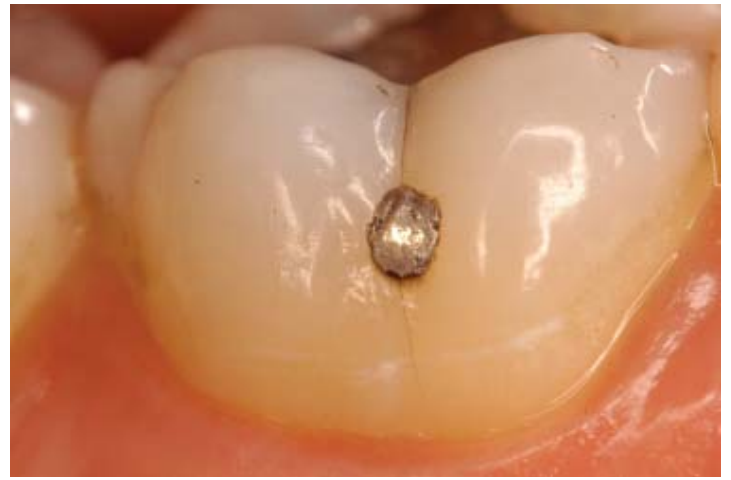

Figure 2. Initial buccal view.

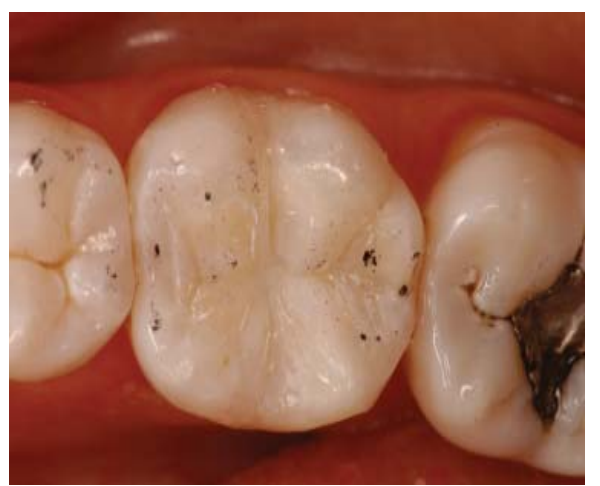

Figure 4. Final restoration after occlusal adjustment.

contacts were adjusted using a polishing cup (Figure 4). After the end of the restorative procedures, the patient was instructed about what foods to avoid in the first 24 hours and was asked to return for evaluation. In the first two weeks, the patient reported a reduction in pain, but it did not disappear. A month later, pain was mild and only felt when the patient had cold or hot foods. At that time, the patient was examined, and occlusion was once again evaluated and adjusted, and the restoration underwent finishing and polishing. Monitoring after that revealed a reduction of symptoms. After seven years, the patient reported no pain. The clinical examination revealed that the restoration remained satisfactory and there were no stains or infiltrations signs (Figure 5). The monitoring radiograph ruled out periodontal lesions or periapical pathologies (Figure 6). 


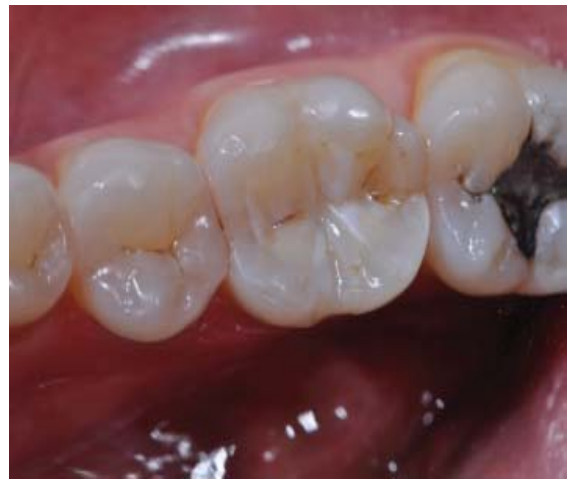

Figure 5. Restored tooth of a 7-year monitoring period.

\section{DISCUSSION}

This report describes a case of unilateral cracked tooth syndrome in the left mandibular first molar of a female patient that was 26 years old, not, therefore in the age group with the highest incidence according to other reports $(30-60$ years) $(3-5,7,9,10,12)$. Such characteristic may be related to the fact that as much as people age, their dentine's fatigue resistance decrease $(7,13)$.

Similarly, to what was observed in this present case report, the lower arch was the most affected by cracked tooth syndrome according to the literature reviewed $(5,10,12)$. The lower molars showed higher incidence of damage by the cracked tooth syndrome $(66,9 \%)$, being $27,82 \%$ and $39,12 \%$, respectively, the first and second lower molars (5). The result endorses Kang et al., findings, which showed a higher incidence of cracked teeth among lower second molars (10). Additional diagnostic radiographs may be used to check possible periapical disease or periodontal lesions, and their findings may be suggestive of a misdiagnosis or inappropriate treatment (4). However, as the fracture in a cracked tooth usually runs mesiodistally, it is not always visible on radiographs. The use of newer methods of analysis, such as cone beam computed tomography (CBCT), to identify longitudinal fractures has been studied, and a recently developed technique to diagnose cracked tooth syndrome uses optical coherence tomography (OCT) $(14,15)$. Crack lines invisible to the naked eye might be seen on OCT scans (15).

Xie et al., alert that, in cases of teeth with highly

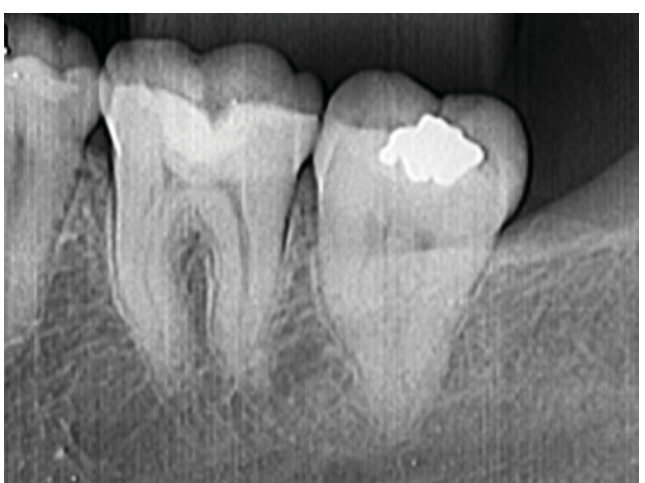

Figure 6. Radiograph of a 7-year monitoring period.

stressed cusp inclinations, the occlusal adjustments are imperative in order to minimize the risk of fractures (6). In this particular clinic case, no stressed cusp inclinations were observed. In our case, the examination of occlusal contacts revealed significant contact points over a larger area than the area of other contacts on the tooth.

The buccolingual crack was fully visible after the removal of the old amalgam restoration. Krell e Caplan observed, in their study, that among 363 teeth affected by the cracked tooth syndrome, $57,9 \%$ had been restored with dental amalgam and $7,7 \%$ with composite resin (5). These authors also report that the higher incidence of cracked teeth occur in restorations involving one surface $(49,5 \%)$. Such results are in agreement with the ones observed in the present clinic case. On the other hand, Kang et al., and Yang et al., diverge by stating that the cracked tooth syndrome takes place mainly on healthy teeth $(10,12)$.

A direct restoration using a composite resin was chosen because adhesive systems produce restorations that reinforce the remaining tooth structure, reducing crack propagation and alleviating symptoms caused by non-moving fluids in the dentinal tubules $(9,14,16)$.

Although the patient complained of pain, and especially thermal sensitivity, in the first month after the treatment, her pain had a low score on a visual analogue scale (VAS). Four years later, the patient had no complaints about mastication or thermal sensitivity. Despite of superficial staining there were no clinical or radiographic signs of marginal leakage, secondary carious lesions or pulp, periodontal or periapical changes. 
It is emphasized that the diagnosis of the pulp condition is straightly related to the treatment plan to be followed by the dental surgeon. This happens due to the diagnosis of irreversible pulp alterations and pulp necrosis linked to dental fractures, representing the most common clinic findings $(71 \%)$ in cases of cracked tooth syndrome (5). Yang et al., also point out that pulp necrosis in cracked teeth is a very common clinic case, when the periodontal probing depth is higher than $4 \mathrm{~mm}$. In this clinic case the pulp condition was diagnosed as reversible and the treatment plan proposed was the most conservative one, which has been proved a successful approach after 7 years of monitoring (12). Therefore, it can be stated that the earlier is the diagnosis, better will be the prognostic to cracked teeth diagnosed with reversible pulpitis. However, due to the high variability of clinical monitored results, dental extraction has been recommended in the literature for cracked teeth with necrotic pulps and slight restorations (11). Yet, such treatment option is not unanimous, as long as there's no probing depths higher than $5 \mathrm{~mm}$ and the treatment plan includes endodontic treatment as well as indirect restoration (5).

Kang et al. (10) had previously also proved the negative influence of the periodontal probing depth higher than $6 \mathrm{~mm}$ for the clinic success of the endodontic treatment associated to the restorative treatment in the cracked teeth, these authors also verified a success rate of $90 \%$ in the two years clinicmonitoring period of cracked teeth endodontically treated and properly restored (10).

The success of the therapeutic approach adopted in this case after diagnosis was confirmed by results in a 7-year monitoring period. In this context, Alkhalifah et al., alert that in advance to the clinic decision taking, it is necessary to establish protocols based on scientific evidences from prospective long-term clinic monitoring in order to achieve safer treatment prescriptions (8).

\section{CONCLUSION}

Direct-bonded restoration should be considered a quick, safe and conservative option for restoring cracked teeth. The diagnosis and treatment of the case described here resulted in complete pain relief and maintenance of normal conditions seven years later.

\section{Corresponding:}

Terezinha Jesus Esteves Barata

E-mail: terezinhabarata@yahoo.com.br

\section{REFERENCES}

1. Banerji S, Mehta SB, Millar BJ. The management of cracked tooth syndrome in dental practice. Br Dent $\mathrm{J}$. 2017;222(9):659-666.

2. Batalha-Silva S, Gondo R, Stolf SC, Baratieri LN. Cracked Tooth Syndrome in an unrestored maxillary premolar: A case report. Oper Dent. 2014; 39(5): 460468.

3. Lago ADN, Albuquerque RC, Poletto LTA, Freitas PM, Garone-Netto N, Lanza LD. Cracked tooth syndrome: literature review. J. Health Sci Inst. 2013; 31(2): 214-218.

4. Banerji S, Mehta SB, Millar BJ. Cracked tooth syndrome. Part 1: etiology and diagnosis. Br Dent J. 2010; 208(10): 459-463.

5. Krell KV, Caplan DJ. 12-month Success of Cracked Teeth Treated with Orthograde Root Canal Treatment. J Endod. 2018;44(4):543-548.

6. Xie N, Wang P, Wu C, Song W, Wang W, Liu Z. Impact of cusp inclinations on dental fractures in cracked tooth syndrome model and relevant risk evaluation. Exp Ther Med. 2017; 14(6):6027-6033.

7. Lubisich EB, Hilton TJ, Ferracane J. Cracked teeth: a review of the literature. J Esthet Restor Dent. 2010; 22(3): 158-167.

8. Alkhalifah S, Alkandari H, Sharma PN, Moule AJ. Treatment of Cracked Teeth. J Endod. 2017;43(9):1579-1586.

9. Banerji S, Mehta SB, Millar BJ. Cracked tooth syndrome; Part 2, restorative options for the management of cracked tooth syndrome. Br Dent J. 2010; 208(11) : 503-514.

10. Kang SH, Kim BS, Kim Y. Cracked teeth: Distribution, characteristics, and survival after root canal treatment. J Endod. 2016;42(4):557-562.

11. Berman LH, Kuttler S. Fracture necrosis: diagnosis, prognosis assessment, and treat- ment recommendations. J Endod 2010;36:442-446.

12. Yang SE, Jo AR, Lee HJ, Kim SY. Analysis of the characteristics of cracked teeth and evaluation of pulp status according to periodontal probing depth. BMC Oral Health. 2017; 17(1):135.

13. Bajaj D, Sundaram N, Nazari A, et al. Age, dehydration and fatigue crack growth in dentin. Biomaterials 2006;27:2507-2517.

14. Kalyan-Chakravarthy PV, Telang LA, Nerali J, Telang A. Cracked tooth: a report of two cases and role of cone beam computed tomography in diagnosis. Case Rep Dent. 2012; 2012: 525-364. 
15. Lee SH, Lee JJ, Chung HJ, Park JT, Kim HJ. Dental optical coherence tomography: new potential diagnostic system for cracked-tooth syndrome. Surg Radiol Anat. 2016; 38(1):49-54.

16. Schwendicke F, Göstemeyer G, Blunck U, Paris S, Hsu LY, Tu YK. Directly Placed Restorative Materials: Review and Network Meta-analysis. J Dent Res. 2016;95(6):613-22.

Recibido: 23-11-2018

Aceptado: 19-02-2019 